\title{
Developing and evaluating an e-learning package for medical students on genocide and public health
}

\author{
Makarious Awad, Sudhir Venkatesan, Heather Roberts, Nicki Keating, Puja Myles
}

Division of Epidemiology and Public Health, University of Nottingham, UK

Correspondence: Sudhir Venkatesan, Division of Epidemiology and Public Health, Clinical Sciences Building, City Hospital, Nottingham NG5 1PB, United Kingdom. Email: Sudhir.Venkatesan@nottingham.ac.uk

\begin{abstract}
Objective: This paper describes the development and evaluation of an e-learning package on the topic of genocide and public health aimed at undergraduate medical students. Methods: An e-learning package was designed based on pedagogical principles and was evaluated in a sample of second-year medical students. Students were asked to rate the usability of the e-learning package (design, interactivity, pace, suitability as a learning mode for the topic). The effectiveness of the e-learning package in relation to achieving learning outcomes was tested via baseline and postlearning activity questionnaires.
\end{abstract}

Results: Out of 253 second-year medical students, 96(38\%) participated in the evaluation of which $45 \%$ gave a score of 9 out of 10 for the e-learning package design, 97\% preferred it as a learning mode over traditional lecture based teaching and $95 \%$ agreed that the package increased understanding of the topic. Immediately following the learning activity 93.75\% of second-years agreed that genocide was a public health issue as opposed to $23.96 \%$ at baseline. $96 \%$ agreed that health professionals had a role in genocide prevention but only $32 \%$ agreed that they had a personal role in genocide prevention.

Conclusions: The evaluation of the e-learning package suggested that learners found it well-designed and a preferred learning mode as compared to traditional lecture based teaching. There was some evidence of positive changes in knowledge and attitudes relating to genocide prevention and the role of public health immediately following the learning activity.

Keywords: Genocide, e-learning, undergraduate medical curriculum, public health

\section{Introduction}

Genocide is defined, according to the United Nations Convention on the Prevention and Punishment of the Crime of Genocide, as "any of the following acts committed with intent to destroy, in whole or in part, a national, ethnic, racial or religious group, as such:

1. Killing members of the group

2. Causing serious bodily or mental harm to members of the group

3. Deliberately inflicting on the group conditions of life calculated to bring about its physical destruction in whole or in part

4. Imposing measures intended to prevent births within the group

5. Forcibly transferring children of the group to another group".
Since the twentieth century, genocide has claimed several million lives. Acts of genocide are humanitarian emergencies and, human rights and health are inseparable..$^{2-4}$ The health outcomes of genocide extend beyond the devastating impact of the crude mortality rate. Genocide often causes shortages of food, water and shelter along with poor sanitation and living conditions. This results in long-term health sequelae which include infectious diseases and malnutrition. ${ }^{2,5,6}$ It is important to realise that health professionals can have a role in the prevention and mitigation of genocide. ${ }^{7,8}$

Genocide prevention is currently not listed as a core learning outcome in the UK undergraduate medical curricu$\operatorname{lum}^{9}$ and is covered rarely within the undergraduate medical course. ${ }^{10}$ Therefore, whilst there is a clear role for health professionals in genocide prevention, they may not be aware 
of this and there may be a case for educating health professionals. Some of the educators within Public Health therefore decided to develop a pilot educational initiative to provide an overview of genocide as a public health issue to test the receptivity of medical students to this concept. Given that this was a pilot initiative combined with existing timetabling constraints, it was agreed that an e-learning package would be the best approach. To make it more relevant and engaging for medical students, the main role in developing the package was assigned to a third year medical student Makarious Awad (MA). Another advantage with an e-learning package designed as a standalone learning module that did not require prior knowledge, would be that it could be made available to other interested learners with a basic understanding of public health even outside of the medical course. This paper reports on a project to design, develop and evaluate an e-learning package on genocide and public health for undergraduate medical students at the University of Nottingham. The evaluation focused on the effectiveness and usability of the e-learning package as an educational intervention.

\section{Methods}

We used the framework advocated by Leeds University for the development and evaluation of the e-learning package. ${ }^{11}$ We also drew on Mayes' conceptualisation cycle, Salmon's five stage model of e-learning and Laurillard's conversational model when designing the e-learning package. ${ }^{12,13}$ A project steering committee comprising MA, Heather Roberts (HR), Puja Myles (PM), and Nicki Keating (NK) agreed on the development and evaluation strategies to be used based on a consensus approach.

\section{Design and development of the e-learning package}

Learners and the context: the e-learning package was mainly aimed at undergraduate medical students but assumed no prior knowledge on the topic. This therefore, made it suitable for anyone with a basic understanding of public health principles and health education. The package incorporated a combination of approaches to accommodate for differences in learning styles. A selection of text, visual imaging, videos, interactive tasks and quizzes throughout the e-learning package were utilized to engage the learner.

\section{Technological aspects of design}

E-learning was selected as a method of delivering the teaching content since it is known to be an appropriate teaching method to introduce novel topics to medical students. ${ }^{14-20}$ E-learning allows the user to access the content virtually anywhere and at any time, as long as an internet connection is available. The package was also designed to allow the slowest of internet connections to support use, and is therefore compatible for use with any device that allows internet access and 'Flash' use.

Xerte Online Toolkits (XOT), an open source e-learning development tool developed by the University of
Nottingham and permitted for use online under the GNU Public License, ${ }^{21}$ was used to develop this e-learning package. XOT is compatible with almost all hardware. The software allows interactive e-learning to be produced with simple tools. In terms of navigation, XOT provides a list of contents on each page that can be accessed at any time during the elearning session. XOT allows for bi-directionality and so users can navigate forwards and backwards using on-screen arrows. Users can also exit the e-learning at any stage and a help facility is available.

The font type, size and colour were consistent throughout the e-learning package to ensure that it was user-friendly without additional distractors. The software allowed the colour scheme, screen size, volume, text size and font to be changed according to the users' individual preferences.

\section{Content and presentation of e-learning}

Suitable learning outcomes were agreed in consultation with genocide experts and education specialists in the university (Table 1). Following a consultation with our e-learning specialists, it was agreed that the maximum duration of the e-learning package should be 30 minutes in keeping with the overall aim to provide an overview of the topic. Much of the textual content within the package was drawn from material from a postgraduate module on this topic. ${ }^{22}$ Genocide is not usually considered to fall within the remit of public health so it was felt that the presentation of the material should follow the typical format used to teach public health problems i.e. defining the problem, describing the problem in epidemiological terms (e.g. herd immunity, risk factors for genocide, levels of prevention etc.) and the public health impact. This was undertaken to encourage the learner to make the connection between genocide and public health concepts.

Table 1. Learning outcomes covered in the e-learning package

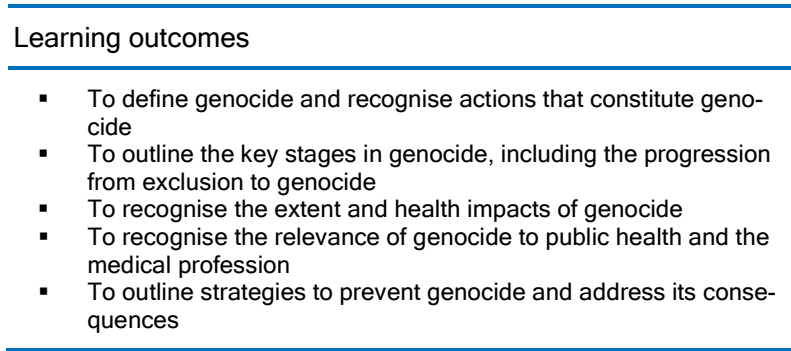

The e-learning package ${ }^{23}$ was designed to accommodate a number of learning styles, through the variation in text, videos, images and interactive learning tasks that enable effective and engaging learning. Interactive tasks also facilitated deep learning rather than mere recollection of facts.

\section{Pilot testing}

The e-learning package was sent to 20 second year medical students for pilot testing and detailed feedback. Fifteen students completed the e-learning package (with the pre and post learning surveys), and the pilot testing feedback questionnaire which included free text response questions. 
Key themes from the pilot evaluation are summarised in Table 2. Minor changes were made to the e-learning package such as technical issues with the interactive tasks, presentation of the material and spelling errors. Some amendments were also made to the pre and post-learning survey questionnaires.

\section{Evaluation approach}

Criteria for evaluating effectiveness and usability: 'effectiveness' was defined as positive changes in knowledge outcomes and attitudes in relation to genocide. A positive change in knowledge outcomes was indicated by an increase in the proportion of students with correct responses after completion of the e-learning package as compared to baseline knowledge scores. A positive attitude was defined as the recognition that genocide was a public health issue, that health care professionals had a role in genocide prevention and a willingness to engage in genocide prevention activities at a personal level. An increase in the proportion of students responding in the affirmative to these options as compared to baseline was considered a proxy measure of 'positive attitudinal change'.

\section{Study design}

In order to evaluate the impact the e-learning package had on knowledge outcomes and change in attitudes related to genocide, a simple pre- and post-learning comparison study was used. This was done by incorporating a pre and postlearning survey questionnaire within the e-learning package itself. The 'usability' of the e-learning package was assessed through questions asked after the e-learning activity was completed.

\section{Study population}

The e-learning package content was designed to be accessible to anyone without prior public health knowledge. For the evaluation a deliberate decision was made to test this package with second year medical students. This was because the second year students would have been exposed to e-learning during their first year and therefore any feedback on the elearning design itself would probably offer a fairer reflection on the specific e-learning package being tested. The elearning package with the embedded pre and post e-learning questionnaires was sent via an online link to all 253 second year medical students at the University of Nottingham for completion. The free version of the commercial survey software Survey Monkey was used for the questionnaires.

\section{Structure of the questionnaire}

The pre e-learning survey consisted of 7 questions: 1 on previous e-learning use, 3 to assess knowledge outcomes and 3 to assess attitudes to genocide. The post e-learning survey consisted of 10 questions: 5 questions on the design and usability of the e-learning package itself, 2 to assess knowledge outcomes and 3 to assess attitudes to genocide (Appendix 1). The questions on knowledge were presented as multiple choice questions with a single best answer. To avoid the risk of testing bias i.e. better post-test performance on a question because of the pre-test rather than the elearning package itself, the knowledge questions were reframed to test the same concepts in a different way. ${ }^{26}$

Table 2. Feedback from the pilot evaluation

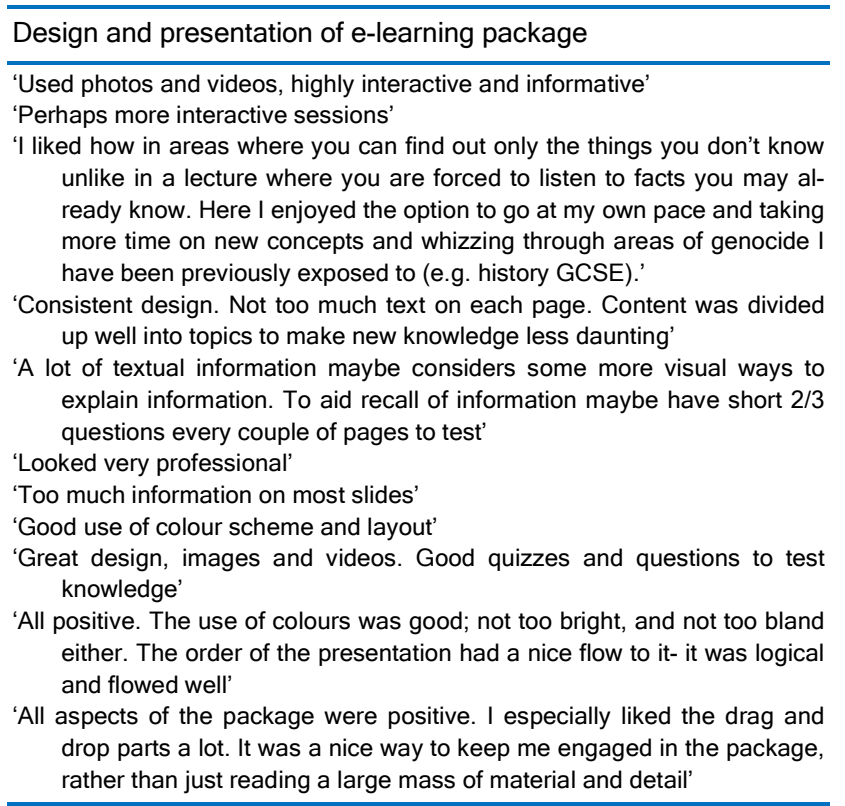

Content of e-learning package

\section{'Very good content'}

'Interesting topic presented with interesting information'

'Very good!!! (-)' (sic)

'Good that it looked at lots of examples but a lot of information to be taken in'

'Very informative content with clear layout'

'Detailed and interesting'

'I liked it a lot. I feel that I actually learnt a good, sufficient deal about genocide. I didn't realise the relation between genocide and public health in medicine until using this package'

Duration and depth of e-learning package

'I think I was losing concentration towards the end but the information was relevant and I felt it was important for it to be there so would rather sacrifice the time to learn about all the stages of genocide and their public health impact'

'(Duration and depth of e-learning package) seemed about right to me'

'Too long. Too much info'

'Very detailed but maybe a bit too much text'

'Good coverage'

'The package was well balanced and contained information which was just right'

'Good length considering the amount of info covered'

'It maintained my interest throughout. I feel that it's too long and had good enough coverage of the topic; good enough breadth and depth of the issue. That's why I chose 5 (on the rating scale)- right in the middle, not too long and the topic coverage amount was just right'

An un-weighted scoring system was used with each correct answer being awarded one mark. For questions assessing attitudes and eliciting feedback on usability, a range of question formats were used including: multi-option questions, dichotomous response questions, interval scale scoring questions and Likert item response type questions. For the Likert item response type questions, the 'neutral' category was eliminated to force respondents to take a position. A deliberate decision was taken based on the pilot testing to use a range of question formats to avoid mechanistic responses. 


\section{Data analysis}

For questions assessing knowledge, the percentage of students getting a correct response before and after the e-learning package was compared. For questions assessing positive attitudinal change in relation to genocide, the proportion agreeing with the options previously described as being positive attitude indicators, before and after the elearning package was compared. For questions assessing usability of the e-learning package, where interval scales (1-10) were used, the median scores were presented with a score above 6 indicating a favourable response. For questions assessing usability of the e-learning package, where Likert item type responses were used, the proportion of students responding 'agree/strongly agree' was compared to those responding 'disagree/strongly disagree'. Constraints on the types of data provided by the free version of Survey Monkey meant that only summary statistics were available and testing for statistical significance was not possible.

\section{Ethics approval}

The Division Education Committee deemed this evaluation exempt from full ethics approval process by the Medical School Ethics Committee as the aim of this project was to improve the student learning experience and involved minimal risk to the participants. A condition of this exemption was that the evaluation would not include randomisation of students to the e-learning package.

\section{Results}

This section presents the evaluation results. The e-learning package was sent to 253 second year students, 98 completed the pre-learning questionnaire but only 96 completed the post-learning questionnaire (total response rate of 38\%) and were included in the evaluation of the e-learning package. The results summarised in Tables 3 and 4 suggest that the e-learning package performed well in terms of user satisfaction, interactivity, design, achievement of learning outcomes, as well as influencing learner attitudes to genocide.

\section{Discussion}

\section{Summary of key findings}

The evaluation results summarised in Tables 2 and 3 show that the e-learning package scored highly on 'usability' in terms of interactivity, pace and delivery of core learning material in an engaging way. The results summarised in Table 4 suggest that there were some short-term gains in genocide related knowledge and positive attitudinal expression immediately following the completion of the e-learning package.
Table 3. Learner feedback on the design and usability of the e-learning package $(n=96)$

\begin{tabular}{lc}
\hline Evaluation question & $\mathrm{n}(\%)$ \\
\hline $\begin{array}{l}\text { The e-learning package has increased my understanding of } \\
\text { the topic }\end{array}$ & $91(94.79)$ \\
$\quad$ Strongly agree/agree & $5(5.21)$ \\
$\quad$ Disagree/strongly disagree & \\
The e-learning package was sufficiently interactive & $94(97.91)$ \\
$\quad$ Strongly agree/agree & $2(2.10)$ \\
$\quad$ Disagree/strongly disagree & \\
How do you feel about the time it took to complete this e- & \\
learning package? & $58(60.4)$ \\
$\quad$ Reasonable & $31(32.3)$ \\
$\quad$ Long & $7(7.3)$ \\
$\quad$ Highly time consuming & \\
Did you find the e-learning package enjoyable (rating scale & \\
1-10)? & \\
$\quad$ Median score & 8.00 \\
$\quad$ Mean score & 7.98 \\
How would you rate the overall presentation and design of & \\
this e-learning package (rating scale 1-10)? & \\
$\quad$ Median score & \\
$\quad$ Mean score & \\
Which learning style would suit you best for developing a \\
good understanding of genocide and public health? \\
$\quad \begin{array}{l}\text { This e-learning package } \\
\text { Classroom lecture }\end{array}$ \\
\hline 1 being the least score (poor) and 10 being the maximum score (excellent) \\
$\quad$
\end{tabular}

\section{Strengths of the Study}

The e-learning package itself was designed to be studentcentred and this was demonstrated in the positive student feedback. The results suggest the effectiveness of the elearning package in improving knowledge and promoting positive attitudes at least in the short-term.

Health professionals are known to have a role to play in genocide prevention, and the evaluation of this educational package has shown its potential use in promoting positive attitudes towards genocide prevention in medical students. Considering the knowledge-attitudes-practice (KAP) model of health behaviour, this would be the first step towards change in behaviour relating to genocide prevention. However this could not be assessed in the evaluation as behaviour change following qualification is a long-term outcome. Moreover, behaviour change, in this case being actions to prevent genocide, is not only dictated by knowledge, but by contextual factors. On the other hand, advocacy for genocide prevention by health professionals educated on this topic is a reasonable goal to expect.

\section{Limitations of the Study}

The response rate to the questionnaire was limited. Out of a class of 253 second year medical students, 98 initially responded to the pre e-learning survey, 2 subsequently dropped out, leaving 96 participants in the stage II evaluation testing (38\% response rate). Considering that the completion of the e-learning package was voluntary, this could be considered a relatively good response rate to generalise findings to the study population. 
Table 4. Comparison of pre- and post-learning scores to assess learning and attitude outcomes among the intervention group $(n=96)$

\begin{tabular}{|c|c|}
\hline Outcome being evaluated & $n(\%)$ \\
\hline \multicolumn{2}{|c|}{ Learning outcome: stages of genocide (correct responses) } \\
\hline $\begin{array}{l}\text { Pre-learning } \\
\text { Post-learning }\end{array}$ & $\begin{array}{c}6(6.25) \\
90(93.75)\end{array}$ \\
\hline \multicolumn{2}{|c|}{$\begin{array}{l}\text { Learning outcome: genocide is a public health issue } \\
\text { (number agreeing) }\end{array}$} \\
\hline $\begin{array}{l}\text { Pre-learning } \\
\text { Post-learning }\end{array}$ & $\begin{array}{l}23(23.96) \\
90(93.75)\end{array}$ \\
\hline \multicolumn{2}{|c|}{$\begin{array}{l}\text { Attitudinal change: health professionals have a role in } \\
\text { genocide prevention (number agreeing) }\end{array}$} \\
\hline $\begin{array}{l}\text { Pre-learning } \\
\text { Post-learning }\end{array}$ & $\begin{array}{l}10(10.41) \\
92(95.83)\end{array}$ \\
\hline \multicolumn{2}{|c|}{$\begin{array}{l}\text { Attitudinal change: personal role in genocide prevention } \\
\text { once qualified as medical doctors (number agreeing) }\end{array}$} \\
\hline $\begin{array}{l}\text { Pre-learning } \\
\text { Post-learning }\end{array}$ & $\begin{array}{c}2(2.08) \\
31(32.29)\end{array}$ \\
\hline
\end{tabular}

The evaluation study used a quasi-experimental approach involving pre- and post-intervention assessments of knowledge and attitudes, which may have caused respondent burden, potentially leading to respondents not taking the survey seriously. Moreover, an inherent bias with all quasiexperimental approaches is self-selection of study participants. It is likely that our study participants already had an interest in the topic of genocide and therefore were more engaged with the e-learning package. This could have led us to overestimate the effectiveness of the e-learning package in achieving learning outcomes. We have already mentioned the threat to internal validity from testing bias, whereby, the pre-intervention test primes the intervention group for better performance in the post-intervention test, irrespective of the intervention.

Another threat to internal validity is the 'history threat' as described by Trochim ${ }^{25}$ where some historical episode rather than the educational intervention could have led to the outcome observed is a common limitation. ${ }^{25}$ However, in this e-learning package there was only one hour between the pre and post e-learning surveys, it is therefore unlikely that another concurrent event could have affected the knowledge or attitude outcomes.

It is worth pointing out that any likely gains in knowledge or expressions of positive attitudes towards genocide prevention following the e-learning package could be purely short-term gains and without further consolidation or the right contextual factors, it is unlikely that long-term knowledge or attitudinal change would result. However, the results do suggest that the e-learning package has served to spark an interest in a topic that may not have been considered relevant by medical students before this point.

Finally, this study evaluated an e-learning package as a learning tool. Although approximately $97 \%$ stated that the elearning package was sufficient to give them a good understanding of the topic as opposed to a traditional lecture and ideally, the study should have evaluated the effectiveness of the e-learning package as compared to a traditional lecture and compared the two styles for their relative outcomes.
However, this is rarely a pragmatic option for practitioner based research limited by timetabling and resource constraints. A parallel survey of third year medical students from the University of Nottingham showed that just over two thirds of respondents $(82 / 121)$ thought that genocide should be part of the public health curriculum and $84 \%$ wanted to learn more about genocide following the survey with their preferred option being e-learning. ${ }^{26}$

\section{Conclusions}

In conclusion, our evaluation of an e-learning package on genocide and public health found that it was well received by students and was associated with short-term knowledge gains and positive attitudes in relation to genocide prevention. We invite other educationalists to use and evaluate this resource with their own students.

\section{Acknowledgements}

We would like to thank Professor Reg Dennick and Sonia Ratib for their helpful comments on our e-learning package. We would also like to thank Steven Stapleton, Joshua Baker and the U-Now team for helping with the process of making our e-learning package available under a creative commons license. Our thanks extend to Dr. Christopher Owens for proofreading our manuscript.

\section{Conflicts of Interests}

The authors declare that they have no conflicts of interest.

\section{References}

1. UN General Assembly. Convention on the prevention and punishment of the crime of genocide. 1948 [cited 20 September 2012]; Available from: http://www2.ohchr.org/english/law/genocide.htm.

2. Willis BM, Levy BS. Recognising the public health impact of genocide. Journal of American Medical Association. 2000;284(5):612-614

3. Mann JM, Gostin L, Gruskin S, Brennan T, Lazzarini Z, Fineberg HV. Health and human rights. Health and human rights. 1994;1(1):06-23.

4. World Health Organisation. Report of the WHO informal consultation on health and human rights. Geneva. 1997 [cited 20 September 2012]; Available from: http://www.who.int/iris/handle/10665/70555.

5. Prunier G. Leave none to tell the story - Genocide in Rwanda. Times Literary Supplement. 1999;5038:30-30.

6. Adler RN, Smith J, Fishman P, Larson EB. To prevent, react, and rebuild: health research and the prevention of genocide. Health services research. 2004;39(6p2):2027-2051.

7. Murray CJ, King G, Lopez AD, Tomijima N, Krug EG. Armed conflict as a public health problem. BMJ. 2002;324(7333):346-349.

8. Hunter E. Genocide: a public health issue. Australian and New Zealand Journal of Public Health. 1996;20(6):565-566.

9. General Medical Council. Tomorrow's doctors. 2009 [cited 10 November 2011]; Available from: http://www.gmc-uk.org/TomorrowsDoctors_2009 .pdf_39260971.pdf.

10. British Medical Association Medical Student. BMA medical student conference. London: British Medical Association;2013.

11. University of Leeds. E-learning usability. 2011 [cited 10 November 2011]; Available from: http://www.leeds.ac.uk/medicine/prof_dev/free/elearning \%20usability_HTML/page_01.html.

12. Joint Information Systems Committee (JISC), University of Northumbria. Models of learning and teaching. 2009 [cited 15 November 2011]; Available from: http://www.jiscinfonet.ac.uk/InfoKits/effective-use-of-VLEs/intro-toVLEs/introtovle-approaches/introtovle-model.

13. University of Manchester. Introduction to e-learning pedagogy. 2008 [cited 10 November 2011]; Available from: http://www.cam 
pus.manchester.ac.uk/medialibrary/elearning/bb_staffdev_intropedagogy_vl _3final.pdf.

14. Sandars J, Schroter S. Web 2.0 technologies for undergraduate and postgraduate medical education: an online survey. Postgraduate Medical Journal. 2007;83(986):759-762.

15. Greenhalgh T. Computer assisted learning in undergraduate medical education. British Medical Journal. 2001;322(7277):40-44.

16. Silva CS, Souza MB, Silva Filho RS, Medeiros LM, Criado PR. E-learning program for medical students in dermatology. Clinics. 2011;66(4):619-622.

17. Tam M, Hart AR, Williams S, Holland R, Heylings D, Leinster S. Evaluation of a computer program ('disect') to consolidate anatomy knowledge: a randomised-controlled trial. Medical teacher. 2010;32(3):e138e142.

18. O’Neill E, Stevens N, Clarke E, Cox P, O’Malley B, Humphreys H. Use of e-learning to enhance medical students' understanding and knowledge of healthcare-associated infection prevention and control. Journal of Hospital Infection. 2011;79(4):368-370.

19. Devitt P, Palmer E. Computers in medical education 1: evaluation of a problem-oriented learning package. Australian and New Zealand Journal Of Surgery. 1998;68(4):284-287.
20. Devitt P, Smith JR, Palmer E. Improved student learning in ophthalmology with computer-aided instruction. Eye. 2001;15(5):635-639.

21. University of Nottingham. Xerte, Open source e-learning. 2008 [cited 10 January 2012]; Available from: http://www.nottingham.ac.uk/xerte/.

22. Roberts H. Genocide and public health [post-graduate course]. Division of Epidemiology and Public Health; Nottingham: University of Nottingham; 2011.

23. Awad M, Venkatesan S, Roberts H, Keating N, Myles P. Genocide and Public Health. University of Nottingham. 2011 [cited 20 September 2012]; Available from: http://tinyurl.com/ak7co8a.

24. Trochim WK. Introduction to e-learning pedagogy. 2008 [cited 10 November 2011]; Available from: http://www.campus.manchester.ac.uk/ medialibrary/elearning/bb_staffdev_intropedagogy_v1_3final.pdf.

25. Trochim WK. Internal Validity. 2006 [cited 28 November 2011]; Available from: http://www.socialresearchmethods.net/kb/intval.php.

26. Bisht S. A cross-sectional survey of medical students' knowledge and attitudes towards major public health problems [B.Med.Sci Degree]. Faculty of Medicine and Health Sciences; Nottingham, UK: University of Nottingham; 2012.

\section{Appendix 1.}

\section{Pilot testing pre e-learning survey}

1. Have you ever used an e-learning package before? Yes

$$
\text { No }
$$

2. What is genocide?

1. Discrimination based on race

2. The systematic destruction of a specific group

3. The ability to oppress minority group members

4. The random killing of individuals for no obvious reason

3. How many people do you think have died in the Darfur genocide?
1. 1500
2. 5000
3. 60000
4. 200000

4. Do you think that health professionals have a role in genocide prevention? Yes

No

5. What is Public Health?

1. The study of infectious diseases

2. To provide the individual patient with the care they need

3. The study of common diseases e.g. cancer, smoking, CHD and how to prevent these

4. Focusing on communities and populations, adopting a proactive preventative approach

6. Do you think genocide is a public health issue?

Yes

No

7. Do you think public health has a role in reducing the disastrous effects caused by genocide?

Yes

\section{Pilot testing post e-learning survey}

1. Did you find the e-learning package enjoyable?

Likert scale $1-10,(1=$ very un-enjoyable and $10=$ highly enjoyable $)$

2. How would you rate the overall presentation and design of this e-learning package?

Likert scale $1-10,(1=$ worst and $10=$ best $)$

3. How many stages are there in genocide?
1. 3
2. 5
3. 8
4. 10

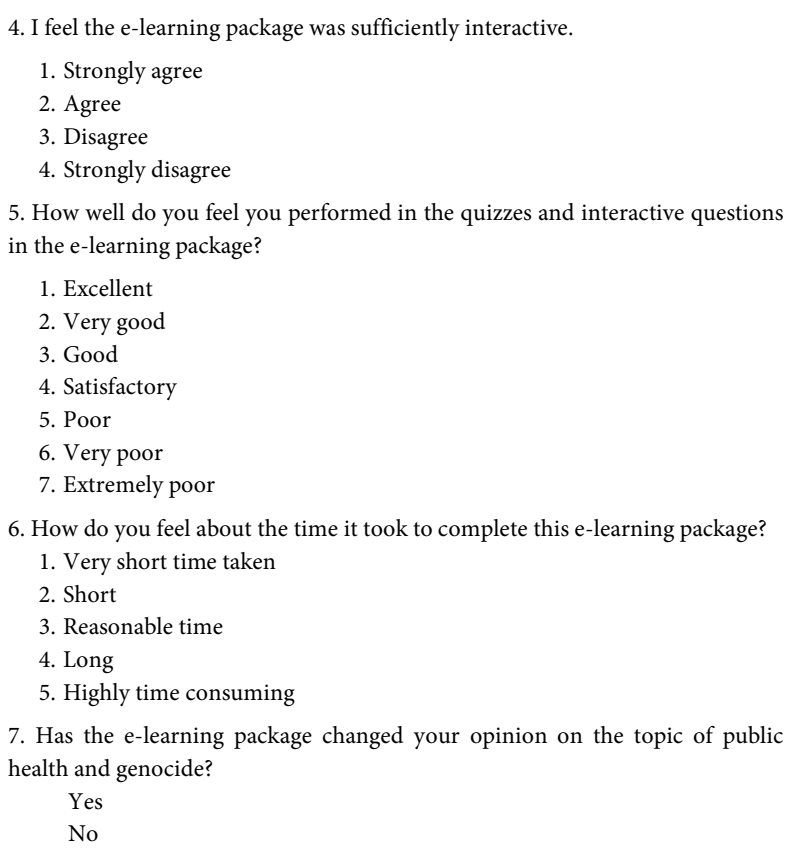

8. Having completed the e-learning package, my understanding has increased and I now feel that public health has a role in preventing and mitigating genocide.

1. Strongly agree

2. Agree

3. Disagree

4. Strongly disagree

9. Do you feel that you have a good understanding of this top or would you better learn this content in a lecture style setting?

Yes, I feel this e-learning package has been sufficient

No, I would learn this topic better in a traditional lecture style setting

10. How long did it take you to complete the e-learning package (including the survey at the beginning and this survey)?

1. Less than 25 minutes

2. 25-30 minutes

3. 30-35 minutes

4. 35-45 minutes

5. More than 45 minutes 